\title{
Polyethylenimine-based micro/nanoparticles as vaccine adjuvants [Corrigendum]
}

Shen C, Li J, Zhang Y, et al. Int J Nano. 2017;12:5443-5460.

The affiliations were presented as:

Chen Shen'
Jun Li'
Yi Zhang'
Yuce $\mathrm{Li}^{2}$
Guanxin Shen
Jintao Zhu'
Juan Tao'

'Department of Dermatology, Union Hospital, Tongji Medical College, Huazhong University of Science and Technology, Wuhan, China; ${ }^{2} \mathrm{School}$ of Chemistry and Chemical Engineering, Huazhong University of Science and Technology, Wuhan, China; ${ }^{3}$ Department of Immunology, Tongji Medical College, Huazhong University of Science and Technology, Wuhan, China
The affiliations should have contained the postcodes and are corrected here:

Chen Shen'

Jun Li'

Yi Zhang'

Yuce $\mathrm{Li}^{2}$

Guanxin Shen ${ }^{3}$

Jintao Zhu ${ }^{2}$

Juan Tao'

'Department of Dermatology, Union Hospital, Tongji Medical College, Huazhong University of Science and Technology, Wuhan 430022, China; ${ }^{2}$ School of Chemistry and Chemical Engineering, Huazhong University of Science and Technology, Wuhan 430074, China; ${ }^{3}$ Department of Immunology, Tongji Medical College, Huazhong University of Science and Technology, Wuhan 430022, China
The International Journal of Nanomedicine is an international, peerreviewed journal focusing on the application of nanotechnology in diagnostics, therapeutics, and drug delivery systems throughout the biomedical field. This journal is indexed on PubMed Central,

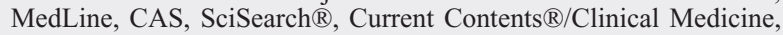

Journal Citation Reports/Science Edition, EMBase, Scopus and the Elsevier Bibliographic databases. The manuscript management system is completely online and includes a very quick and fair peer-review system, which is all easy to use. Visit http://www.dovepress.com/ testimonials.php to read real quotes from published authors. 